\title{
Reduction of Serum Lipid Profile by Escitalopram in Depressive Patients: A Cardio Protective Aspect of SSRI Use
}

\author{
Ashique Ali Arain ${ }^{1 *}$, Abdul Rahim Memon ${ }^{1}$, Humayion Kazi² and Barkat Ali Mashori ${ }^{2}$ \\ ${ }^{1}$ Department of Pharmacology, Isra University Hyderabad, Pakistan \\ ${ }^{2}$ Sir C. J. Institute of Psychiatry, Pakistan
}

Submission: March 18, 2017; Published: April 13, 2017

*Corresponding author: Ashique Ali Arain, Assistant Professor Department of Pharmacology, Isra University Hyderabad, Sindh, Pakistan, Tel: 009233333389250; Email: ashiquepcmd77@yahoo.com

\section{Abstract}

Background: Depression is disturbance of mood, speech and thoughts interfering with the individual's social life and negatively affecting the family and thus the whole society. Suicide is the most horrible complication ending the life of the patient. Escitalopram belongs to the SSRIs, the most commonly used group of antidepressants worldwide.

Objective: To explore the effects of Escitalopram treatment on lipid profile in patients with depression.

Methodology: This experimental study of 6 months duration was conducted in Sir C.J Institute of Psychiatry Hyderabad and Isra Research Laboratory from July 2016 to December 2016. 72 diagnosed patients of depression were selected through non probability purposive sampling After ethical approval and informed consent blood sample were collected under a septic measures. Samples were analyzed for total cholesterol, HDL, LDL and TAGs before intervention. 8 patients were dropped out from study as they lost follow up after 1 month. Same test were repeated in 64 patients who completed the study while after 6 weeks. Student's t-test was used as statistical technique data was analyzed on SPSS version 21.

Results: There was significant reduction in total cholesterol, LDL and TGs when compared with the pretreatment values P-values $0.01,0.01$ and 0.004 respectively. But there was no significant difference in HDL levels before and after treatment P-value 0.43 .

Conclusion: Treatment with Escitalopram is associated with significant reduction in lipid profile.

Keywords: Escitalopram; Low density lipoprotein; High density lipoprotein; Triglycerides

\section{Introduction}

Depression is a very common and ancient mental disorder prevalent all over the world since centuries affecting all age groups of both male and female genders. It is the 4 th most serious public health problem worldwide with about 350 million people being affected and expected to be the most common mental disorder by year 2020 [1]. Depression has a wide range of symptoms that include low mood, negative thoughts, pessimism, guilt, and ugliness, indecisiveness, lack of interest and motivation, decreased sexual desire, appetite and sleep [2]. Depressive patients end their lives through suicide as a Complication of the disease. Suicide rates vary from country to country with Hungary on top where the rate is 58/100, 000 followed by, USA 20/100000 and Spain9/100000 every year. Prevalence of depression has long been studied in different populations that were found as ranging from $5 \%$ in general population and $10 \%-20 \%$ in chronic sick patients [3]. It is $3 \%$ $8.7 \%$ prevalent in children and $25 \%$ in pregnant women [4].
Students show a prevalence of 53.43\% in Pakistan while 26.2\% in Turkey [5]. Depression is also a risk factor for atherosclerosis in addition to smoking, physical inactivity, obesity and dyslipidemia [6]. The ideal treatment plan for depression consists of pharmacotherapy, psychological and educational interventions [7]. There are many pharmacological treatment options for depression like Tricyclic antidepressants (TCAs), mono amine oxidase inhibitors (MAOIs), Selective serotonin norepinephrine inhibitors (SNRIs), selective serotonin reuptake inhibitors (SSRIs) and atypical antidepressants [8]. SSRIs are most popular as they are safe, more tolerable, cheaper and due to their spectrum of indication other than depression [9]. It is also used to treat the premature ejaculation [10]. Escitalopram is derived from Citalopram with a bioavailability of $80 \%$ and halflife of 27-32 hours makes it once daily dosage of $10-20 \mathrm{mg} /$ day [9]. It is recommended to check total cholesterol, LDL-C, HDL-C and triglycerides in patients which are at risk of atherosclerosis 
[11]. Few previous researches pointed out depression to be associated with disturbed lipid profile and such patients are more violent and prone to suicide [12]. Vaan Reed Dortland et al. [13] from Netherland also reported abnormal lipid pattern in depression. High levels of total cholesterol, LDL-cholesterol as well triglycerides were observed by Liang Y et al. [14] in depressive patients. As the duration of therapy is longer in depressive patients there is need of studies to observe effects of escitalopram on lipid profile that are not studied well in human so far. This additional information may help the depressed patients with comorbid conditions like ischemic heart diseases and dyslipidemia.

\section{Methodology}

Depressive patients were selected from Sir Cowasjee Institute of Psychiatry Hyderabad Sindh, Pakistan after informed written consent. The study project was approved from the ethical review committee of the Isra University. Fasting blood samples were taken from the antecubital vein under aseptic measures. Samples were brought to Isra university hospital laboratory for biochemical analysis. Lipid studies were done on Hitachi automatic analyzer after obtaining serum through the centrifugation of whole blood at 3000 round per minutes.

\section{Statistical Analysis}

Data analysis was accomplished using SPSS (Statistical Package for Social Sciences) version 21. Mean and standard deviation were calculated for the numerical variables. Paired sample t-test was used to compare the means of the pre and post treatment value of TC, LDL, HDL and TGs.

\section{Result (Figure 1)(Table 1)}

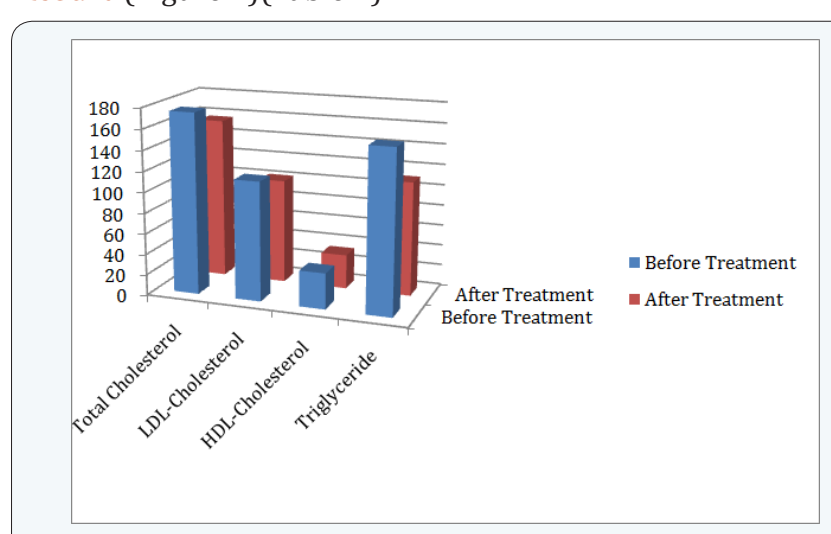

Figure 1: Study conducted regarding the lipid profile effects of a well-known antidepressant Escitalopram.

Table 1: Comparison between pre and post treatment lipid profile $(n=64)$.

\begin{tabular}{|c|c|c|c|}
\hline Parameters & $\begin{array}{c}\text { Pre } \\
\text { Treatment }\end{array}$ & $\begin{array}{c}\text { Post } \\
\text { Treatment }\end{array}$ & P-Value \\
\hline Total Cholesterol (mg/dl) & $175.17 \pm 1.50$ & $156 \pm 35.90$ & 0.01 \\
\hline HDL-Cholesterol (mg/dl) & $34.77 \pm 10.17$ & $33.25 \pm 11.84$ & 0.43 \\
\hline LDL-Cholesterol (mg/dl) & $115.31 \pm 33.40$ & $101.28 \pm 26.80$ & 0.01 \\
\hline Triglyceride (mg/dl) & $156.69 \pm 0.25$ & $110.61 \pm 53.68$ & 0.004 \\
\hline
\end{tabular}

\section{Discussion}

Serotonin reuptake inhibitors have been used for very long period and they are associated with excellent results regarding reduction in the depressive symptoms in depressive patients. They are drugs of interest. Depression is a very disturbing mental health disorder of the world in all age groups of both male and female sex disturbing lives and ending into suicide of 1 million people every year [15]. Our community has a poor knowledge about depression including the health care providers [16]. Escitalopram is the first line choice SSRI, superior in efficacy and well tolerated by the patient 90. Its metabolic effects are of great interest as the drug is commonly used for longer periods. Our study is the first human study conducted in Pakistan regarding the lipid profile and glucose effects of a well-known antidepressant Escitalopram. However there are few studies available on the same parameters but they were limited and controversial due to comorbidities. Our study was purely based on depressive patients provided by the consultants Psychiatrists of the Sir Cowasjee Jahangir Institute of Psychiatry Hyderabad Sindh, Pakistan.

\section{Total cholesterol}

Our 6 weeks study showed a reduction in serum total cholesterol that was in contrast to findings of Jana Radojkovic et al. [17] reporting no significant reduction in total cholesterol. This may be due to the fact that the study population was diabetic in his work. However our findings were consistent with AminaUnis et al. [18]. Who declared a significant decrease in total cholesterol after 6 weeks treatment with Escitalopram in an animal model. M Beyazyaz et al. [19] in his relatively longer duration study (16 weeks) also reported a reduction in serum total cholesterol following Escitalopram treatment that is in accordance with our results.

\section{HDL-cholesterol}

Our study reported a non-significant reduction in HDL levels which is in contrast to results of study by Amin Unis et al. [18] which shows a significant increase in HDL levels. Our results are in accordance with the results of M Beyazyaz et al. [19] who also reported no significant effects of Escitalopram on serum HDL concentration. As we know the HDL cholesterol is beneficial cholesterol so it should not be reduced but should be increased studies proved so far that Escitalopram either increases the HDL levels or if reduces but not to significant levels.

\section{LDL-cholesterol}

Low density cholesterol was reduced in our study which is in accordance with the study by Amina Unis et al. [18] which also showed a significant reduction in LDL cholesterol. Similarly our results are also consistent with the findings of M Beyazyaz et al. [19] who also reported a significant in LDL cholesterol.

\section{Triglycerides}

There is highly significant reduction in triglyceride levels in our study which in accordance with the results of Jana 
Radojkovic et al. [17] who also concluded a significant decrease in triglyceride levels. Our results are also consistent with the results of Amina Unis et al. [18] which showed a significant reduction in serum triglyceride level after treatment with Escitalopram. Results of the study by M Beyazyaz et al. [19] showed an increase in the triglyeride levels which is in contrast to our findings. All studies discussed so far lack a common feature that none of them explained the possible mechanism of reducing the lipid profile. This remained a weakness of our study as well and a gape for the future researchers to work on. Escitalopram may have some inhibitory effect on lipolipase an enzyme responsible for breakdown of fats into fatty acids and triglycerides. It may also possess some activity at LDL receptors increasing its uptake all needs further exploration.

\section{Conclusion}

Parameters of lipid profile (TC, LDL, TGs) are significantly reduced in depressive patients on Escitalopram treatment however HDL-cholesterol remained unchanged (nonsignificant).

\section{Recommendations}

a) The use of Escitalopram is recommended for depressive patients with dyslipedimia as well as cardiac patients.

b) It is recommended to explore the exact mechanism behind the lipid lowering effects of Escitalopram.

\section{References}

1. Orzechowska A, Filip M, Gałecki P (2015) Influence of Pharmacotherapy on Cognitive Functions in Depression: A Review of the Literature. Med Sci Monit 21: 3643-3651.

2. Rang HP, Ritter JM, Flower RJ, Henderson G (2016) Antidepressant drugs. In: Rang and Dale's Pharmacology. Churchill Livingstone Elsevier, UK, pp. 571-588.

3. Walker BR, Colledge NR, Ralston SH, Ian D (2014) Medical Psychiatry. In: Davidson's Principals and Practice of Medicine. Penman, Churchill Livingstone, Elsevier, New York, USA, pp. 231-258.

4. Bendiksen B, Aase H, Diep LM, Svenssonn E, Friis S, et al. (2015) The Associations Between Pre- and Postnatal Maternal Symptoms of Distress and Preschooler's Symptoms of ADHD, Oppositional Defiant Disorder, Conduct Disorder, and Anxiety. Journal of Attention Disorders 1-13.

5. Ghayas S, Shamim S, Anjum F, Hussain M (2014) Prevalence and Severity of Depression among Undergraduate Students in Karachi, Pakistan: A Cross Sectional Study. Trop J Pharm Res 13(10): 17331738.
6. Camacho Á, McClelland RL, Delaney JA, Allison MA, Psaty BM, et al. (2016) Antidepressant Use and Subclinical Measures of Atherosclerosis. The Multi-Ethnic Study of Atherosclerosis. J Clin Psychopharmacol 36(4): 340-346.

7. Abbas A, Rizvi SA, Hasan R, Aqeel N, Khan M, et al. (2015) The prevalence of depression and its perceptions among undergraduate pharmacy students. Pharmacy Education 15(1): 57- 63.

8. Cipriani A, Purgato M, Furukawa TA, Trespidi C, Imperadore G, et al. (2014) Citalopram versus other anti-depressive agents for depression. Cochrane Database Syst Rev (7): CD006534.

9. Katzung BG, Masters SB, Anthony (2012) Antidepressant Agents. In: Basic and Clinical Pharmacology, J Trevor McGraw Hill Companies, New York, USA, pp. 521-539.

10. Koyuncu H, Serefoglu EC, Yencilek E, Atalay H, Akbas NB, et al. (2011) Escitalopram treatment for premature ejaculation has a negative effect on semen parameters. International Journal of Impotence Research 23: $257-261$.

11. KibbaKoumare A, Guira A, Samandoulougou A, Kabré E, Sondé I, et al. (2015) Plasma lipid profile including the high density lipoprotein (HDL), subclasses in hypertensive patients in Ougadougou, Burkina Faso. African Journal of Biochemistry Research 9(3): 47-54.

12. Patra BN, Khandelwal SK, Chadda RK, Ramakrishnan L (2014) A controlled study of serum lipid profile in indian patients with depressive episodes. Indian J Psychol Med 36(2): 129-133.

13. van Reed Dortland, Gilty EJ, Van Veen T, van Pelt J, Zitman FG, et al. (2010) Association between Serum Lipids and Major Depressive Disorder: Results from Netherland's Study of Depression and Anxiety. J Clin Psychiatry 71(6): 729-736.

14. Liang Y, Yan Z, Cai C, Jiang H, Song A, et al. (2014) Association between lipid profile and depressive symptoms among Chinese older people: mediation by cardiovascular disease. Int J Behav Med 21(4): 590-596.

15. Zahidie A, Jamali T (2013) An Overview of the Predictors of Depression among Adult Pakistani Women. J Coll Physicians Surg Pak 23(8): 574580 .

16. Jafri MA, Minhas FA, Tamiz-ud-Din A, Slatch MA, Mujeeb F (2011) Knowledge of Depression among Community Members and Health Care Providers in Two Selected Areas of District Rawalpindi. J Coll Physicians Surg Pak 21(12): 756-759.

17. Radojkovic J, Sikanic N, Bukumiric Z, Tadic M, Kostic N, et al. (2016) Improvement of Glycemic Control in Insulin-Dependent Diabetics with Depression by Concomitant Treatment with Antidepressants. Med Sci Monit 22: 2133-2143.

18. Unis A, Abdelbary A, Hamza M (2014) Comparison of the effects of escitalopram and atorvastatin on diet-induced atherosclerosis in rats. Can J Physiol Pharmacol 92(3): 226-233.

19. Beyazyüz M, Albayrak Y, Eğilmez OB, Albayrak N, Beyazyüz E (2013) Relationship between SSRIs and Metabolic Syndrome Abnormalities in Patients with Generalized Anxiety Disorder: A Prospective Study. Psychiatry Investing 10(2): 148-154. 
This work is licensed under Creative Commons Attribution 4.0 License DOI: $10.19080 /$ JOCCT.2017.04.555642
Your next submission with Juniper Publishers will reach you the below assets

- Quality Editorial service

- Swift Peer Review

- Reprints availability

- E-prints Service

- Manuscript Podcast for convenient understanding

- Global attainment for your research

- Manuscript accessibility in different formats ( Pdf, E-pub, Full Text, Audio)

- Unceasing customer service

Track the below URL for one-step submission https://juniperpublishers.com/online-submission.php 